\title{
Reliability and validity of the Arabic version of the Early Onset Scoliosis 24 Items Questionnaire (EOSQ-24)
}

\author{
Yahia Hanbali ${ }^{1}$, Tony Perry ${ }^{2}$, Asif Hanif ${ }^{3}$, Hiroko Matsomotu ${ }^{4}$, Haytham Musmar ${ }^{1}$, Khaldoun Bader ${ }^{5}$, \\ and Alaaeldin Azmi Ahmad ${ }^{6, *}$
}

${ }^{1}$ Faculty of Medicine and Health Sciences, An-Najah National University, Nablus 41414, Palestine

2 Assistant Program Manager, Waltham Forest Clinical Commissioning Group, London, E11, UK

3 Asst. Prof. \& Head of Department, Bio-Statistics, GD-PGMI, 54000, Pakistan

${ }^{4}$ Department of Orthopaedic Surgery, Columbia University Medical Center, 630 West 168th Street, \#1504, 10032, New York City, NY, USA

5 Assistant Professor in Epidemiology, School of Public Health, Al-Quds University 90612, Palestine

6 Pediatric Orthopedic Surgeon, Associate Professor, Poly Technique University-Palestine, PO Box 3985, Ramallah, West bank, 602, Palestine

Received 14 July 2018, Accepted 8 January 2019, Published online 8 February 2019

\begin{abstract}
Introduction: Early Onset Scoliosis (EOS) is a complex pathology that covers a variety of etiologies, with onset before the age of 10 years. Surgical treatment of EOS should have the objectives of fulfilling maximum pulmonary function, spine length, with minimal hospitalizations, complications, and family burden. Radiographic parameters are an important standard in assessing treatment outcomes. However, the Early Onset Scoliosis Questionnaire-24 (EOSQ-24) was developed to measure the wider dimensions of outcomes involving the quality of life of patients and caregivers post-treatment. The aim of this study was to evaluate the validity and reliability of culturally adapted Arabic version of the EOSQ-24.

Methods: Translation and cross-cultural adaptation, based on published guidelines, were performed on the original English EOSQ-24 by a committee. The Arabic version of EOSQ-24 was applied to the caregivers of all 58 EOS patients who were treated surgically after signing a consent form. Reliability was assessed using Cronbach's $\alpha$ and item-total statistics for the whole questionnaire initially and for the each domain separately. Data quality was assessed by mean, median, percentage of missing data, ceiling and floor effects. Discriminative validity was examined using non parametric tests.

Results: The response for all items was excellent with only $1.7 \%(0-1)$ of responses missing. The floor effect ranged from $0 \%$ to $36.2 \%$ of patients and the ceiling effect ranged from 0 to $46.6 \%$. Cronbach's $\alpha$ test reliability was found excellent (0.919), as was the internal consistency of all domains, with Cronbach $\alpha$ ranging from 0.903 to 0.918 . Corrected itemtotal correlations were good for all domains (>0.3). Only one item (Question 21) showed low corrected item-total correlations $(r=0.222)$. However, Cronbach's $\alpha$ did not increase significantly when this item was deleted $(0.920)$.

Conclusion: The first adapted Arabic version of EOSQ-24 is found to have good validity and reliability, and it can be used to assess children in Arab societies with EOS.
\end{abstract}

Key words: Early onset scoliosis, Arabic version, Early Onset Scoliosis-24 Questionnaire, Health-related quality of life, Validation, Validation.

\section{Introduction}

Early Onset Scoliosis (EOS) is a complex pathology that covers a variety of etiologies including idiopathic, neuromuscular, syndromic, and congenital types, with onset before the age of 10 years [1]. Its natural history is associated with progressive deterioration in pulmonary function and poor quality of life.

\footnotetext{
*Corresponding author: alaaahmad@hotmail.com
}

In addition, EOS patients may have associated pathological cardiopulmonary and gastrointestinal conditions that exacerbate the burden of spinal deformity on pulmonary function, if left untreated $[2,3]$.

Current options for the treatment of EOS aim to stop the progression of curve as well as give the spine and the thorax an opportunity to grow [4]. Technological advances have significantly improved the growth-friendly spinal implants, which aim to correct the abnormal curvature, while maintaining the 
growth of the spine and the thorax. The safety and efficacy of growth-friendly techniques in the treatment of EOS, in addition to improvements in the quality of life in EOS patients, have been documented in the literature [5,6]. Growing instrumentation "growing rod" (GR) and "vertical expandable prosthetic titanium rib" (VEPTR) are spine-based and rib-based distractions, respectively, utilized as an alternative to arthrodesis $[7,8]$. These growing methods have shown promising results, although they have negative impacts on the health of children due to repetitive surgeries [9-11].

For many years, the assessment of quality of life for EOS patients depended on radiographic parameters that show progression of curve. However, with a growing interest on the impact of treatment on health-related quality of life, outcome measures that assess the subjective response of patients to their disease, as well as the burden on the caregivers, are considered an important part of health assessment [12,13].

Matsumoto et al. [14] developed Early Onset Scoliosis-24 Questionnaire (EOSQ-24) as a tool for evaluation of both patients and parents. EOSQ-24 showed a picture of quality of life pre and post operatively. The questionnaire was developed in English language, and after it showed good internal consistency and reliability, it was modified into its current version [15].

EOSQ-24 needs to be culturally adapted to retain consistency and validity for the assessment of a new population. This is particularly important for uncommon disorders, such as EOS, where multicenter multinational cooperation is fundamental to amass a larger patient series and compare results at a multicenter level [16].

Previous studies have shown the validity and reliability of EOSQ-24, either in its original language [14] or after it was translated into Turkish, Spanish, and Chinese languages [17-19]. The authors recognized a need to create an Arabic version of the EOSQ-24 [14].

The aim of this study was to translate the original EOSQ-24 into Arabic, and to test the reliability and discriminative validity of the Arabic version of EOSQ-24. Discriminative validity was used since there is no valid questionnaire in Arabic that deals with children's health.

\section{Methods}

The Early Onset Scoliosis-24 (EOSQ-24) is a survey instrument used to assess the quality of life of children who have early onset scoliosis (EOS). It is a subjective questionnaire completed by parents on behalf of child patients. The EOSQ24 consists of 24 questions with 11 domains: general health, pain, pulmonary function, transfer, physical function, daily living, fatigue, emotion, parental burden, financial burden, and satisfaction [14].

We ran through all the files for the cases with EOS that had surgery done for management.

All of the families were contacted and the questionnaire was filled either personally or by phone. It took one year to complete the data (2016).

\section{Study design}

The authors contacted the original developers to confirm that no other groups were translating the EOSQ-24 into the Arabic language, and obtained permission to carry out this translation.

There were two different stages for this study: First, the EOSQ-24 was translated into Arabic and transculturally adapted, following the best practice guidelines described by Beaton et al. [20] and accepted by the developers of the questionnaire. Second, the information was collected from patients' caregivers. All ethical considerations were taken care of by the ethics committee of An-Najah National University, and a consent form was signed by parents of each child.

\section{Cross-cultural adaptation and translation process}

The questionnaire was translated from English to Arabic by two native Arabic speakers fluent in English, one an orthopedist and the other with no medical background. A third independent committee reviewed both translations. The committee was comprised of a pediatric orthopedic surgeon, two orthopedic surgeons, and translators to find discrepancies between the two translation to create a pretesting Arabic version of the EOSQ-24.

The pretesting Arabic form was tested on a sample of patients to prove that they could understand each question clearly and to make changes to questions that were not clear. The form was then translated back by two native English speakers with good Arabic knowledge. Both were blinded to the purpose of the study and had no access to the original questionnaire. The committee finalized the pretesting form after discussing all translations, and added modifications to any ambiguous expressions.

The final version was tested on the entire available sample by interviewing the 58 parents of children. We asked them if the questions were relevant to their child's condition and confirmed their understanding of the questions.

\section{Data analysis}

Each question in the Arabic version of questionnaire was scored on a 5-point Likert scale, with higher scores indicating lower disability. Moreover, a score for each domain was calculated. All statistical analyses were performed using SPSS (Statistical Package for the Social Sciences) software version 20.0. Categorical variables were represented by percentages, while continuous variables were reported as median and interquartile ranges. Internal consistency, validity, and ceiling and floor effects were also analyzed in this study.

\section{Internal consistency}

Internal consistency was assessed using the Cronbach $\alpha$ coefficient, which is used to measure how closely related questions within a survey or a given subset of survey questions are. This is consistent with the approach taken for testing the original EOSQ-24 survey. The recommended value for Cronbach $\alpha$ is between 0.70 and 0.95 [21]. 
Internal consistency was also assessed using Item-total correlations and inter-item correlations. Item-total correlations explore how each item is related to other items in the scale; 0.3 or higher is considered good correlation in the domain [21-23]. Inter-item correlations give an indication that the items are too similar; a good range for inter-item correlations is between 0.2 and 0.8 [21-23].

\section{Ceiling and floor effects}

Ceiling and floor effects were used to determine the ability of the questionnaire to assess severity condition, while descriptive statistics (mean values, and quartiles) were calculated to show distribution for domains. Analysis was done by calculating the frequency of extreme possible scores, with values less than $30 \%$ considered acceptable [24].

\section{Discriminant validity}

Discriminant validity was tested for each domain with a range of combinations of patient data, including: Radiographical indices (Cobb angle before surgery), gender, type of Scoliosis (congenital, idiopathic, neuromuscular, and syndromic), ambulatory status, and whether there were complications. The non-parametric Kruskal-Wallis and Mann-Whitney $U$ tests were used to compare between different groups of patients, while the Spearman correlation coefficient was used to find correlation between quantitative parameters. $P$ values less than 0.05 were considered statically significant.

\section{Results}

The 58 caregivers completed the EOSQ-24 questionnaire after they agreed to participate, and signed a consent form explaining the objective of the survey. The caregivers completed the surveys. The clinical and demographic characteristics are summarized in Table 1.

\section{Translation and transcultural adaptation}

There were some cases where translators had difficulty identifying a conceptually equivalent word to capture the meaning of the original question. Questions 8 and 12 were particularly difficult, so the wording of these questions was reviewed and tested carefully to ensure their meaning was clear and conceptually consistent with the original English version.

\section{Internal consistency}

Cronbach's $\alpha$ was used to find the internal consistency of all items of questionnaire and of each domain separately, which included: general health, pain, pulmonary function, mobility, physical function, daily living, fatigue, emotion, parental burden, financial burden, and satisfaction.

Cronbach's $\alpha$ for all items showed an excellent overall reliability with 0.919 . Corrected item-total correlation was also calculated for each question, and the results were within the acceptable range (0.357-0.735), except for question 21
Table 1. Characteristics of patients surveyed using EOSQ-24.

\begin{tabular}{ll}
\hline Characteristic & Value (number of patients) \\
\hline Gender & \\
Male \% & $32.76 \%(19)$ \\
Female \% & $67.24 \%(39)$ \\
Median age at surgery & 62 months \\
Complications \% & \\
Yes & 50 \\
No & 50 \\
Diagnosis \% & \\
Congenital & $39.66 \%(23)$ \\
Syndromic & $25.86 \%(15)$ \\
Neuromuscular & $22.41 \%(13)$ \\
Idiopathic & $12.07 \%(7)$ \\
Ambulatory \% & \\
Yes & $91.4 \%(53)$ \\
No & $8.6 \%(5)$ \\
Site of main curve \% & \\
Thoracic & $36.2 \%(21)$ \\
Thoracolumbar & $58.6 \%(34)$ \\
Lumbar & $5.2 \%(3)$ \\
Number of Curves \% & \\
1 & $44.8 \%(26)$ \\
2 & $48.3 \%(28)$ \\
3 & $6.9 \%(4)$ \\
\hline
\end{tabular}

(0.222). Cronbach's $\alpha$ if Item Deleted ranged between 0.912 and 0.920 and Cronbach's $\alpha$ if Item Deleted for the domain ranged between 0.903 and 0.918 (Table 2).

\section{Ceiling and floor effects}

Ceiling and Floor effects were calculated to ensure that the questions had sufficient variability for differentiating between responses and adequately measuring correlations between variables. Ceiling and floor effects below $30 \%$ were considered acceptable. Several of the questions (notably questions 5, 6, $7,9,10$, and 18) exceeded the threshold for ceiling effects, but all questions met the threshold for floor effects. This resulted in a floor effect in $0 \%-36.2 \%$ of patients and a ceiling effect in $0 \%-46.6 \%$ (Table 3), and may reflect a higher severity of disease for the children tested at this hospital in Palestine.

\section{Response distribution}

Median scores for questions ranged between 2.0 (Q17) and 4.1 (Q5), while the mean score of domains were between 40.5 (Financial Impact) and 72.8 (Pulmonary Function), as shown in Table 3 . This is based on a very high responsiveness to questions; only $1.7 \%$ of questions had missing answers.

\section{Discriminative validity}

In this study, we analyzed variables that had an association with the scores of the Arabic version of EOSQ-24. Patients involved in this study had severe curves, so $60^{\circ}$ was set as the cutoff-point for radiographical indices (Cobb scores). Patients with curves below $60^{\circ}$ had much better scores in comparison to patients with curves above $60^{\circ}(p=0.039)$; 
Table 2. Tests for Internal Consistency.

\begin{tabular}{|c|c|c|c|c|}
\hline Domains & $\begin{array}{c}\text { Scale mean } \\
\text { if item deleted }\end{array}$ & $\begin{array}{l}\text { Scale variance } \\
\text { if item deleted }\end{array}$ & $\begin{array}{c}\text { Corrected item-total } \\
\text { correlation }\end{array}$ & $\begin{array}{c}\text { Cronbachs a if item } \\
\text { deleted }\end{array}$ \\
\hline General health & & & & .912 \\
\hline Q1 & 79.53 & 237.735 & .483 & .917 \\
\hline Q2 & 79.24 & 237.628 & .655 & .914 \\
\hline Pain/discomfort & & & & .913 \\
\hline Q3 & 79.42 & 234.063 & .601 & .914 \\
\hline Q4 & 79.20 & 237.459 & .555 & .915 \\
\hline Pulmonary function & & & & .905 \\
\hline Q5 & 78.64 & 233.236 & .721 & .912 \\
\hline Q6 & 79.11 & 232.247 & .713 & .912 \\
\hline Transfer & & & & .913 \\
\hline Q7 & 79.07 & 229.032 & .665 & .913 \\
\hline Physical function & & & & .903 \\
\hline Q8 & 79.31 & 238.662 & .525 & .916 \\
\hline Q9 & 78.82 & 231.114 & .677 & .913 \\
\hline Q10 & 79.18 & 231.929 & .588 & .915 \\
\hline Daily living & & & & .912 \\
\hline Q11 & 79.33 & 234.928 & .509 & .916 \\
\hline Q12 & 79.35 & 232.786 & .578 & .915 \\
\hline Fatigue/energy level & & & & .906 \\
\hline Q13 & 79.47 & 235.291 & .735 & .913 \\
\hline Q14 & 79.18 & 234.226 & .680 & .913 \\
\hline Emotion & & & & .918 \\
\hline Q15 & 79.67 & 242.224 & .357 & .919 \\
\hline Q16 & 78.98 & 239.685 & .459 & .917 \\
\hline Parental impact & & & & .913 \\
\hline Q17 & 80.76 & 239.295 & .544 & .915 \\
\hline Q18 & 79.00 & 241.926 & .445 & .917 \\
\hline Q19 & 79.16 & 244.251 & .435 & .917 \\
\hline Q20 & 79.11 & 245.136 & .458 & .917 \\
\hline Q21 & 79.25 & 251.082 & .222 & .920 \\
\hline Financial impact & & & & .917 \\
\hline Q22 & 80.20 & 238.607 & .445 & .917 \\
\hline Satisfaction & & & & .914 \\
\hline Q23 & 79.80 & 240.607 & .464 & .917 \\
\hline \multirow[t]{2}{*}{ Q24 } & 79.62 & 231.759 & .562 & .915 \\
\hline & & & $\mathrm{a}$ & $0.919^{*}$ \\
\hline
\end{tabular}

* Alpha coefficients for the total EOSQ scales.

Figure 1A. Moreover, we examined Spearman's correlation and found a weak negative correlation between the total score of Arabic version of EOSQ-24 and Cobb angles. $(\rho=-0.276$ with $p=0.038$ ); Figure 1B.

Regarding complications, we found that patients who had complications after surgery had lower scores when compared to patients who had not $(p=0.035)$. Finally, regarding ambulatory status of patients, we found higher scores in ambulatory patients compared to non-ambulatory patients $(p=0.02)$. No significant results were found for other variables.

\section{Discussion}

Although EOS is considered an uncommon illness, early treatment is mandatory. If left untreated, EOS will lead to increased severity of curves, which increases pulmonary morbidity and cardiovascular problems due to lack of development of the trunk. Quality of life as well as life expectancy decreases dramatically for untreated patients. Surgical treatment options aim to halt progression of curves and maintain the ability of the spine to continue growing, with positive effects on respiratory systems $[4,9,25]$. On the other hand, treatment options may have negative effects on the quality of health if they involve repetitive surgeries $[5,11]$. Matsumoto et al. also found negative effects on the psychosocial aspects for the patient and the family [26]. Therefore, it was necessary to find instruments to assess health-related quality of life of patients and their caregivers.

For many years, in part because of heterogeneity of this population, there was no specific tool to assess the HealthRelated Quality of Life (HRQoL) for EOS patients and the burden on their caregiver. The EOSQ-24 survey was designed to meet this need $[9,10]$, and was originally developed in English.

The Arabic language is an official language in 22 countries with more than 400 million people. To the best of our knowledge, this is the first study that describes cross-cultural adaption and translation of the EOSQ-24 survey into the Arabic 
Table 3. Ceiling and floor effects of Arabic EOSQ-24 ( $n=58)$.

\begin{tabular}{|c|c|c|c|c|c|c|}
\hline Domain & Response & Missing \% & Mean & Median & Ceiling & Floor \\
\hline General health & & & 61 & 62.5 & & \\
\hline Q1 & 58 & 0 & 3.3 & 3.0 & $17.2 \%$ & $8.6 \%$ \\
\hline Q2 & 58 & 0 & 3.6 & 4.0 & $10.3 \%$ & $5.2 \%$ \\
\hline Pain/discomfort & & & 64.2 & 62.5 & & \\
\hline Q3 & 58 & 0 & 3.5 & 3.5 & $24.1 \%$ & $8.6 \%$ \\
\hline Q4 & 57 & 1.7 & 3.6 & 4.0 & $29.8 \%$ & $3.5 \%$ \\
\hline Pulmonary function & & & 72.8 & 75 & & \\
\hline Q5 & 58 & 0 & 4.1 & 4.0 & $46.6 \%$ & $3.4 \%$ \\
\hline Q6 & 58 & 0 & 3.7 & 4.0 & $32.8 \%$ & $1.7 \%$ \\
\hline Transfer & & & 68.1 & 75 & & \\
\hline Q7 & 58 & 0 & 3.7 & 4.0 & $34.5 \%$ & $10.3 \%$ \\
\hline Physical function & & & 68.8 & 75 & & \\
\hline Q8 & 58 & 0 & 3.6 & 4.0 & $20.7 \%$ & $5.2 \%$ \\
\hline Q9 & 58 & 0 & 4.0 & 4.0 & $43.1 \%$ & $6.9 \%$ \\
\hline Q10 & 57 & 1.7 & 3.6 & 4.0 & $33.3 \%$ & $8.8 \%$ \\
\hline Daily living & & & 62.1 & 68.8 & & \\
\hline Q11 & 58 & 0 & 3.5 & 4.0 & $27.6 \%$ & $12.1 \%$ \\
\hline Q12 & 58 & 0 & 3.5 & 4.0 & $24.1 \%$ & $10.3 \%$ \\
\hline Fatigue/energy level & & & 61.6 & 62.5 & & \\
\hline Q13 & 58 & 0 & 3.3 & 3.0 & $10.3 \%$ & $3.4 \%$ \\
\hline Q14 & 58 & 0 & 3.6 & 4.0 & $25.9 \%$ & $1.7 \%$ \\
\hline Emotion & & & 62.3 & 62.5 & & \\
\hline Q15 & 57 & 1.7 & 3.1 & 3.0 & $14.0 \%$ & $12.3 \%$ \\
\hline Q16 & 57 & 1.7 & 3.8 & 4.0 & $38.6 \%$ & $3.5 \%$ \\
\hline Parental impact & & & 57.9 & 60 & & \\
\hline Q17 & 58 & 0 & 2.0 & 2.0 & $3.4 \%$ & $36.2 \%$ \\
\hline Q18 & 58 & 0 & 3.8 & 4.0 & $31.0 \%$ & $1.7 \%$ \\
\hline Q19 & 58 & 0 & 3.6 & 4.0 & $13.8 \%$ & $5.2 \%$ \\
\hline Q20 & 58 & 0 & 3.7 & 4.0 & $13.8 \%$ & $0.0 \%$ \\
\hline Q21 & 58 & 0 & 3.6 & 4.0 & $0.0 \%$ & $5.2 \%$ \\
\hline Financial impact & & & 40.5 & 25 & & \\
\hline Q22 & 58 & 0 & 2.6 & 2.0 & $8.6 \%$ & $20.7 \%$ \\
\hline Satisfaction & & & 53.9 & 50 & & \\
\hline Q23 & 57 & 1.7 & 3.0 & 3.0 & $10.5 \%$ & $5.3 \%$ \\
\hline Q24 & 58 & 0 & 3.3 & 4.0 & $24.1 \%$ & $12.1 \%$ \\
\hline
\end{tabular}
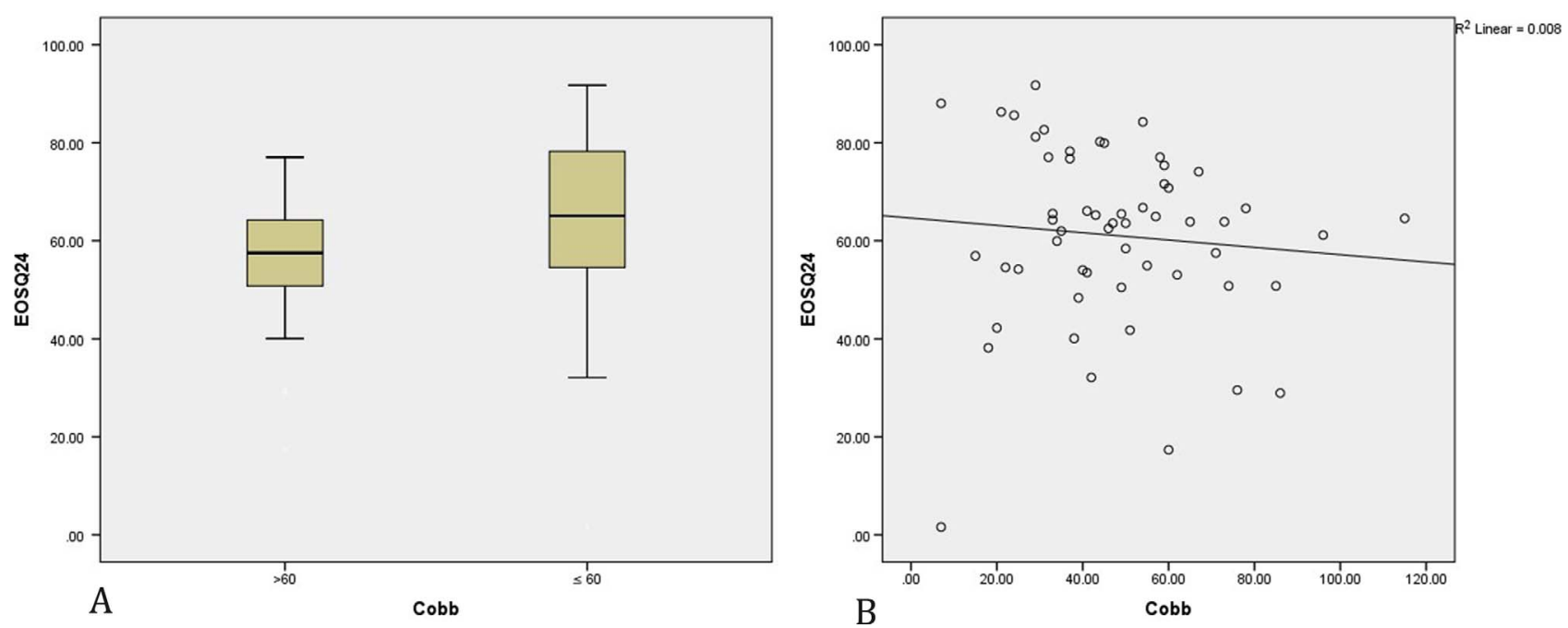

Figure 1. (A) Comparison of total scores between EOS patients with Cobb angle $\leq 60^{\circ}$ and $>60^{\circ}$ were performed using Mann-Whitney $U$ test. (B) Correlation between total scores and Cobb angles were evaluated using a Spearman rank correlation coefficient test. 
language. The survey was translated into Arabic using a rigorous process of translation, back-translation, and testing for reliability and discriminative validity. Our results show excellent reliability as well as an assessment of cross-sectional differences according to several clinical features, such as Cobb angles, ambulatory status, and complications.

Cronbach's $\alpha$ was used to test the internal consistency of the Arabic Version of EOSQ-24, which was very good across the 24 items and 11 domains. The internal consistency for the original EOSQ-24, as measured by Cronbach's $\alpha$, was 0.92 [14]. By comparison, the internal consistency of our Arabic version, as measured by Cronbach's $\alpha$, was 0.919 . This is much closer to the original version than other translated versions of questionnaire, which include Chinese (Cronbach $\alpha$ : 0.896), Turkish (Cronbach $\alpha$ : 0.909), and Spanish (Cronbach $\alpha$ : 0.897) versions.

Cronbach $\alpha$ of items deleted for each question in our study varied from 0.912 to 0.920 , while in Turkish it ranged from 0.902 to 0.908 and in Spanish from 0.802 to 0.898 . Moreover, the corrected item-total correlation was $0.357-0.735$ in our study with only one question below 0.3 . By contrast, in Spanish the correlation ranged between 0.354 and 0.675 with two questions below 0.3 , while in Turkish it ranged between 0.272 and 0.698 with one question below 0.3 .

With respect to floor and ceiling effects, our study revealed a floor effect in $0-36.2 \%$ of patients and a ceiling effect in $0-46.6 \%$. This compares favorably to the other language versions of EOSQ-24. The floor effect in the Turkish version ranged from 0 to $21.7 \%$ of patients, while the ceiling effect ranged from $1.6 \%$ to $68.3 \%$. In the Spanish version, the floor ranged from 0 to $29.5 \%$ and the ceiling ranged from $9.1 \%$ to $74.4 \%$. While the Chinese version had a floor range of $0-26 \%$, and a ceiling range of $0-71 \%$.

The correlation between total scores and Cobb angles in our study was $\rho=-0.276$ with $p=0.038$; this is considered weak but is still an acceptable correlation. In the Spanish study, $\rho=-0.473$ with $p=0.004$, was considered a moderate correlation.

The item-total correlations were found able to show discriminative validity for all questions except Q21, which is regarding parental burden. Q21 also had the lowest reliability $(0.222)$ mostly due to heterogeneity of population and a more severe form of scoliosis. Both Q5 and Q21 had low reliability; that was also due to the heterogenicity for Q21, and the severity of the scoliosis in all cases

Similar to the Spanish study, the Arabic version of EOSQ24 was able to discriminate between EOS patients according to severity of curves, complications after surgery, and ambulatory status. As all participants in the study were treated surgically because of severe curvature, we found that the increment in curve will lower the total score, through a negative relation between score and Cobb angles. In addition, patients who had complications after surgery had a lower score. Non-ambulatory patients also had lower total scores, though this was questionable because only $8.6 \%$ of participants were non-ambulatory.

The heterogeneity of our EOS population, consisting of patients of various ages, disorders, and stages of treatment, can explain the wide range of distribution of scores among parents' answers. Ceiling effects were found in some questions, which concern pulmonary function and physical aspects.
This may be due to the severity of curvature that required surgical treatment in all cases.

\section{Limitations of the study}

1. It is an experience of one center with one surgeon's work.

2. All patients were surgical cases with severe scoliosis.

3. All patients had the same insurance and most of them had similar socioeconomic status.

\section{Conclusion}

The Arabic version of EOSQ-24 provides a reliable tool to assess children with EOS. However, acknowledging the limitations of this study, future studies should be conducted with multicenter data with fewer variables and more homogenous diagnosis.

\section{Conflict of interest}

All authors declare that they have no conflict of interest.

\section{Supplemental material}

Valid and Adapted Arabic translation of the original English Early Onset Scoliosis Questionnaire EOSQ24.

The Supplemental material is available at https://sicot-j.org/10.1051/sicotj/2019001/olm.

\section{References}

1. Williams BA, Matsumoto H, McCalla DJ, Akbarnia BA, Blakemore LC, Betz RR, Flynn JM, Johnston CE, McCarthy RE, Roye DP Jr, Skaggs DL, Smith JT, Snyder BD, Sponseller PD, Sturm PF, Thompson GH, Yazici M, Vitale MG (2014) Development and initial validation of the Classification of EarlyOnset Scoliosis (C-EOS). J Bone Joint Surg Am 96, 1359-1367.

2. Fernandes P, Weinstein SL (2007) Natural history of early onset scoliosis. J Bone Joint Surg Am 89(Suppl 1), 21-33.

3. Pehrsson K, Larsson S, Oden A, Nachemson A (1992) Longterm follow-up of patients with untreated scoliosis. A study of mortality, causes of death, and symptoms. Spine (Phila Pa 1976) 17, 1091-1096.

4. Thompson GH, Akbarnia BA, Campbell RM Jr (2007) Growing rod techniques in early-onset scoliosis. J Pediatr Orthop 27, 354-361.

5. Akbarnia BA, Marks DS, Boachie-Adjei O, Thompson AG, Asher MA (2005) Dual growing rod technique for the treatment of progressive early-onset scoliosis: a multicenter study. Spine (Phila Pa 1976) 30, S46-S57.

6. Akbarnia BA, Breakwell LM, Marks DS, McCarthy RE, Thompson AG, Canale SK, Kostial PN, Tambe A, Asher MA, Growing Spine Study G (2008) Dual growing rod technique followed for three to eleven years until final fusion: the effect of frequency of lengthening. Spine (Phila Pa 1976) 33, 984-990.

7. Klemme WR, Denis F, Winter RB, Lonstein JW, Koop SE (1997) Spinal instrumentation without fusion for progressive scoliosis in young children. J Pediatr Orthop 17, 734-742. 
8. Smith JT (2007) The use of growth-sparing instrumentation in pediatric spinal deformity. Orthop Clin North Am 38(547-552), vii.

9. Emans JB, Caubet JF, Ordonez CL, Lee EY, Ciarlo M (2005) The treatment of spine and chest wall deformities with fused ribs by expansion thoracostomy and insertion of vertical expandable prosthetic titanium rib: growth of thoracic spine and improvement of lung volumes. Spine (Phila Pa 1976) 30, S58-S68.

10. Thompson GH, Akbarnia BA, Kostial P, Poe-Kochert C, Armstrong DG, Roh J, Lowe R, Asher MA, Marks DS (2005) Comparison of single and dual growing rod techniques followed through definitive surgery: a preliminary study. Spine (Phila Pa 1976) 30, 2039-2044.

11. Sankar WN, Acevedo DC, Skaggs DL (2010) Comparison of complications among growing spinal implants. Spine (Phila Pa 1976) 35, 2091-2096.

12. Vitale MG, Matsumoto H, Roye DP Jr, Gomez JA, Betz RR, Emans JB, Skaggs DL, Smith JT, Song KM, Campbell RM Jr (2008) Health-related quality of life in children with thoracic insufficiency syndrome. J Pediatr Orthop 28, 239-243.

13. Vitale MG, Levy DE, Moskowitz AJ, Gelijns AC, Spellmann M, Verdisco L, Roye DP Jr (2001) Capturing quality of life in pediatric orthopaedics: two recent measures compared. J Pediatr Orthop 21, 629-635.

14. Matsumoto H, Williams B, Park HY, Yoshimachi JY, Roye BD, Roye DP Jr, Akbarnia BA, Emans J, Skaggs D, Smith JT, Vitale MG (2018) The final 24-Item Early Onset Scoliosis Questionnaires (EOSQ-24): validity, reliability and responsiveness. J Pediatr Orthop 38(3), 144-151.

15. Matsumoto H, Park HY, McCalla D, Yoshimachi J, Roye D, Akbarnia B, Emans JB, Skaggs D, Smith J, Vitale MG (October 2013) The Early-Onset Scoliosis 24 Item Questionnaire (EOSQ24) reflects changes in quality of life and parental burden after growing rod surgery. Quality of Life Research 22.

16. Guillemin F, Bombardier C, Beaton D (1993) Cross-cultural adaptation of health-related quality of life measures: literature review and proposed guidelines. J Clin Epidemiol 46, 1417-1432.
17. Demirkiran HG, Kinikli GI, Olgun ZD, Kamaci S, Yavuz Y, Vitale MG, Yazici M (2015) Reliability and Validity of the Adapted Turkish Version of the Early-onset Scoliosis-24-Item Questionnaire (EOSQ-24). J Pediatr Orthop 35, 804-809.

18. Del Mar Pozo-Balado M, Matsumoto H, Vitale MG, PraenaFernandez JM, Farrington DM (2016) Reliability and validity of the adapted Spanish version of the Early-Onset Scoliosis-24 Questionnaire. Spine (Phila Pa 1976) 41, E625-E631.

19. Cheung JP, Cheung PW, Wong CK, Samartzis D, Luk KD, Lam CL, Cheung KM (2016) Psychometric validation of the Traditional Chinese Version of the Early Onset Scoliosis-24 Item Questionnaire (EOSQ-24). Spine (Phila Pa 1976) 41, E1460-E1469.

20. Beaton DE, Bombardier C, Guillemin F, Ferraz MB (2000) Guidelines for the process of cross-cultural adaptation of selfreport measures. Spine (Phila Pa 1976) 25, 3186-3191.

21. Terwee CB, Bot SD, de Boer MR, van der Windt DA, Knol DL, Dekker J, Bouter LM, de Vet HC (2007) Quality criteria were proposed for measurement properties of health status questionnaires. J Clin Epidemiol 60, 34-42.

22. Nunnally JBI (1994) Psychometric Theory. New York, McGraw-Hill.

23. Kline P (1993) A Handbook of Test Construction: Introduction to Psychometric Design. Routledge: London, UK.

24. Kane RL. 1997. Understanding Health Care Outcomes Research, 2nd edn. Aspen Publishers: Gaithersburg.

25. Vitale MG, Matsumoto H, Bye MR, Gomez JA, Booker WA, Hyman JE, Roye DP Jr (2008) A retrospective cohort study of pulmonary function, radiographic measures, and quality of life in children with congenital scoliosis: an evaluation of patient outcomes after early spinal fusion. Spine (Phila Pa 1976) 33, $1242-1249$.

26. Matsumoto H, Williams BA, Corona J, Comer JS, Fisher PW, Neria Y, Roye BD, Roye DP, Vitale MG (2014) Psychosocial effects of repetitive surgeries in children with early-onset scoliosis: Are we putting them at risk? J Pediatr Orthop 34, $172-178$.

Cite this article as: Hanbali Y, Perry T, Hanif A, Matsomotu H, Musmar H, Bader K \& Azmi Ahmad A (2019) Reliability and validity of the Arabic version of the Early Onset Scoliosis 24 Items Questionnaire (EOSQ-24). SICOT-J, 5, 7 